\title{
Application of Mobile Phone in Agricultural Marketing in Bangladesh
}

\author{
Md. Momenul Huq ${ }^{1}$ Kanij Farhana ${ }^{2}$, Ananna Rahman ${ }^{3}$ \\ ${ }^{I}$ Research Student, Department of Marketing, Hajee Mohammad Danesh Science and Technology University, \\ Bangladesh \\ ${ }^{2}$ Research Student, Department of Marketing, Hajee Mohammad Danesh Science and Technology University, \\ Bangladesh \\ ${ }^{3}$ Research Student, Department of Finance and Banking, Hajee Mohammad Danesh Science and \\ Technology University, Bangladesh
}

\begin{abstract}
This study is basically a qualitative study in nature. It examined the uses of mobile phone in performing the agricultural marketing activities in Bangladesh. It evaluated the traditional and new application of mobile hand set in the marketing for agricultural operation in the stated country. It is basically used to collect and disseminate the market information about the product. It helps to keep the information and maintain balance between supply and demand of the commodity. But now a day, it does not work only by information but also make easily and modernize the marketing activities for the agricultural product. Recently it contributes more to the every sphere of marketing like product, price place, promotion and developing the market base. Now the farmers of Bangladesh used mobile phone to search the sources of suppliers of seed, medicine and fertilizer as well as the market in home and abroad. It also tests the validity and use ability of seed and medicine by the mobile hand set. Moreover, they enjoy the agricultural news from the different electronic and print media through the mobile phone. Now they can make forecast about the probable change of weather and take necessary steps for the effectiveness of their activities. After all, the mobile phone technology has dramatically changes the marketing activities for the agricultural products.
\end{abstract}

Key Words: Mobile Phone, Uses, Agricultural Product, Marketing Operation

\section{Introduction}

Being a third world country, the importance of agricultural marketing sector has long been recognized by the Government of Bangladesh. The population of Bangladesh is depending their living on agriculture business. Most of the developing countries $40 \%$ of the people are related with agriculture sector (Lanjouw J. O. and Lanjouw P., 2001). Now a day Mobile phones has provided new approach to farmers to make tentative decisions such more easily than before. Mobile phone technology has developed significantly in the past few years. The subscription rate in increase day by dayin the developing countries. Mobile phone is devices that can store, access and share information anytime anywhere. Mobile phone technology helps to create a good communication with rural and urban populations in developing countries and provides latest information about market, weather, natural disaster and other related issues (Aker and Mbiti, 2010). Most of the farmers of Bangladesh are still lack of information and modern agricultural knowledge. Most of the farmers need easy access of information like element, availability, access and utilization. Mobile technology that creates opportunities for rural farmers to obtain information and knowledge about market, agricultural issues, problems and suggest how to develop the agricultural Market. Mobile services in agricultural sector provides more information on market, weather, transport service and agricultural techniques that helps to contact with the agencies and department (Aker, 2011). Phone could be good device to make strong relationship with all agriculture business stakeholders by communication, SMS, email thus benefiting farmers by timely market information to increase the income and decrease the poverty. Now a day's mobile technology has increased rapidly and it spread to the remote areas of the thirds worlds developing countries.

\section{Objectives of The Study}

The main objective of the study is to know the uses of mobile phone in agricultural sector of Bangladesh. With the light of the main objective I also considered the following specific objectives:

1. To know the nature of agricultural marketing in Bangladesh.

2. To know the uses of mobile phone in different sectors of agricultural marketing in Bangladesh.

3. To measure the attitude of the people toward the services of mobile phone in the application of agricultural marketing.

4. To access the new ways for using the mobile phone to the agricultural marketing in Bangladesh. 


\section{Literature Review}

With the huge technological development adoption of mobile phone breaks out like a revolution. This trend has been also spread into the farmers. They are using mobile in exchanging market information's, weather report and business information. By the blessings of technology the farmers can directly with the brokers or agent to sell their products.In developing countries with the increase of mobile phone based social networking, it becomes to be a vital factor of agricultural development. This type of technology allowing better connectivity offers and benefits to the farmers. (Bayes et al., 1999, Donner, 2006)

The farmers who had no mobile phones were facing many problems in selling their products and getting market related information in comparison to farmers who use phone users. In rural areas most of the farmers cannot contact with the agricultural experts due to lack of communication. These peoples still depending on conventional methods of communications like voice amplification, posters etc. sometimes the information might not reached to its targeted audience by this methods. This evident signifies that communications is the main problem faced by the farmers. (Duncombe, 2011).In some developing countries technology is still very expensive. For this reason poor farmers and entrepreneurs could not afford a mobile phone. (Frempong et al., 2007).The cost of mobile phone and its maintenance cost such a big factor for rural people. Moreover, there are some issues detected that the pattern to using mobile phone by this group is different and the scope to the access of market information is very low. (Ashraf et al., 2005, de Silva, 2008).

In developing countries rural community particularly farmers were facing various challenges and obstacles in using information technology tools like mobile phone. Some to these challenges are technical, financial, social and illiteracy. The big issues in developing ICT programs in rural areas are the lack of interest in private sector entrepreneur and low quality service rendered by the company. Lack of technological knowledge was a big problem in the development and use of technology. As the majority of the rural people are illiterate they cannot learn and run technological tools like mobile phone properly. (Samuel et al., 2005,).

Agricultural extension department working out to stimulating the desirable agricultural outcomes by transferring knowledge to farmers, advising and training in their decision making, enabling farmers to setting their own goals and possibilities. There are numerous extension programs are being introduced to overcome the barrier in the adoption of technology in comparing with the less successive public sector extension programs ( Aker et al., 2010).

The peoples of developing countries of the world largely depends agricultural production. The rural farmers and the small entrepreneurs are facing a lot of problems due to the recent price hikes and fluctuations in food sector. Famers and small entrepreneurs had no way to know the price before they go to the market and this is because poor communication facilities. In addition, the poor market structure, inadequate market experience and lack of agricultural inputs keeps the rural farmers behind their capabilities.

\section{Research Methodology}

In performing any applied research a clear and specific methodology has to be followed where methodology is a set of methods sample size, sample selection procedure, process of collecting data, interpreting data, analyzing the data, other relevant activities and combination of rules and techniques have been used. The nature of the study is qualitative. As a result, mainly secondary data were used to conduct the study. But to meet the requirements of specific objective I also used primary data. For the current Study, the farmers are considered as the sample for the study. The researcher has utilized stratified random sampling to assemble the sample for the study. Moreover, researcher has also utilized this method to assemble the sample to measure the service quality of mobile phone in agricultural marketing. Northern part of the country is the main supplier for the agricultural products where Dinajpur is one of the important districts for producing the agricultural products. As a result for the convenience and betterment of the study I have mainly selected sample area as Dinajpur District in Bangladesh. Data have been collected from 100 respondents and the response rate was 90\%. Among them 50 respondent have been selected for pre testing questionnaire.

\section{Nature of agricultural marketing in Bangladesh}

\section{Findings Of The Study}

Agriculture is the biggest single industry in every less developed country. The marketing systems of agriculture which known as the heart of the economic growth process in less development countries. Agricultural production and consumption play an important role in any developing countries economy. Production that's contributes to GDP, and consumption that's represent the part of consumer. Agricultural marketing services involves in moving an agricultural product from the farm to the consumer. There are a lot of intermediary task like, planning production, growing and harvesting, grading, packing, transport, storage, food processing, distribution, advertising and sale etc. Agricultural marketing systems are dynamic. They are always competitive and involve continuous change and improvement. Some businesses which have lower costs, are more efficient, deliver quality products, and are those that prosper. Some business which have high costs, fail to 
adapt to changes in market demand and provide poorer quality are often forced out of business. Agriculture marketing is customer-oriented and it has provided the farmer, transporter, trader, processor, etc, with a profit. This process involved in marketing chains to understand buyer requirements as well as product and business conditions also.

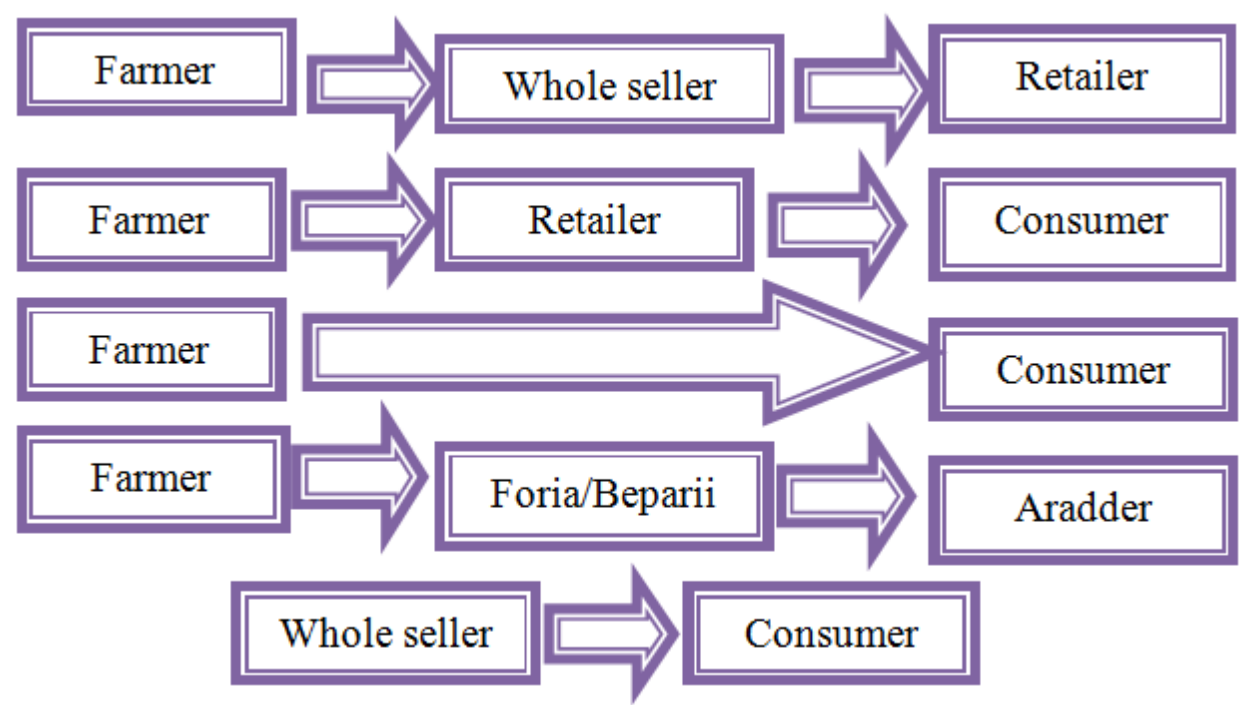

Figure 1: Traditional Distribution System for the Agricultural Product (Developed by the author).

\section{Uses of mobile phone in different sectors of agricultural marketing in Bangladesh}

- Mobile phones provide farmers latest information about prices of crops before they travel long distances to markets.

- Mobile phones ensure farmers can negotiate deals with traders and improve their timing of getting crops to the market.

- Mobile technology provides farmers with crucial weather data so they can properly manage their crops.

- Farmers get a package of information and that their needs and priorities change throughout the production cycle.

- The mobile phone's help potential for reducing asymmetries of information between traders and producers, lowering transaction costs, and enhancing farmers' ability to fine-tune their production strategies to match the accelerating rates of change in consumer demand and marketing channels.

- Farmers used mobile phones to improve income from farms and other rural businesses and build trust with trading partners.

- Mobile phone is helpful to create innovative partnership that gives the facility of direct communication with corporations and traders, or through the ability to supply product based on just-in-time or quality needs.

- Suppliers can use mobile phones to conduct real-time market research, and entire truckloads can be bought and sold while still on the road.

- Mobile phone helps the increased monitoring and coordination of freight transport operations, including product collection, delivery, and security.

- Farmers get the facility of more efficient use of existing storage, packaging, transport, and processing facilities through mobile phones.

- Mobile phone has been more useful for perishable crops and that farmers have gained particularly from being able to arrange transportation more efficiently.

\section{Product Management Decision:}

Product Information

Price Determination

Arrangement for Transportation

Sharing global information

Value Addition

Sharing risk

Treatment of Product

Searching Market

Making Grading and Standardization
Settlement of Price:

Accurate Price Determination

Collecting Price Information

Easy Payment System

Allocating Price Information

Developing Pricing Policy

Price Adjustment 
Quality Control

Capturing Market

Geographical Attachment.

Distribution of Agricultural products through mobile phones

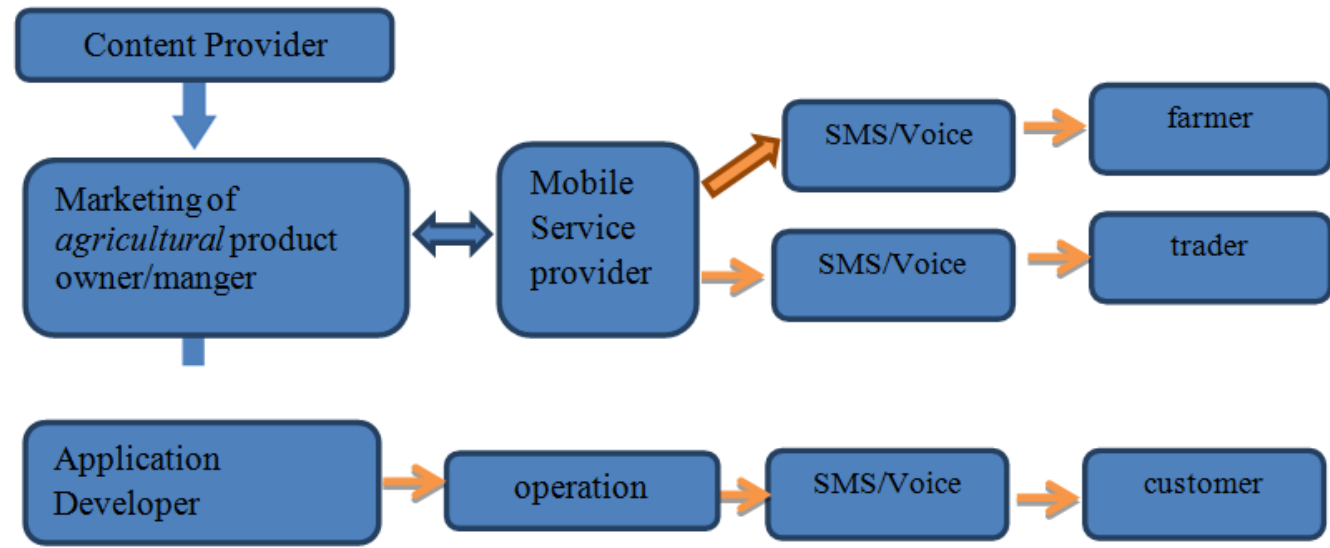

Figure 2: Basic Mobile Agriculture services \& Agents involvement in Mobile marketing

\section{Promoting Activities}

- Mobile Advertising for Agricultural Products

- Individual Promotion

- Instant Display

- Easy Purchase Decision

Measuring the attitude of people towards the services of mobile phone applied to accomplish the agricultural marketing in Bangladesh

\begin{tabular}{|l|l|c|c|c|}
\hline S.L & \multicolumn{1}{|c|}{ Factors } & Ei & bi & eibi \\
\hline 1 & Market Information & 1.5500 & 5.1900 & 8.0445 \\
\hline 2 & Immediate Medication Service of Crops & 0.9300 & 4.7100 & 4.3803 \\
\hline 3 & Transportation Information & 1.2200 & 4.6700 & 5.6974 \\
\hline 4 & Storage \& Maintenance & 0.7700 & 4.1900 & 3.2263 \\
\hline 5 & Weather Anticipation & 1.4400 & 5.1200 & 7.3728 \\
\hline 6 & Insects and Danger kits Identification and Solution & 0.9200 & 4.8400 & 4.4528 \\
\hline 7 & Procuring Seed \& Fertilizer & 1.1400 & 4.4700 & 5.0958 \\
\hline 8 & Display \& Communication & 1.2700 & 4.8000 & 6.096 \\
\hline 9 & Supplier Selection \& Solicitation & 0.6000 & 4.2000 & 2.52 \\
\hline 10 & Mobile Advertising \& Promotion & 1.5300 & 4.8000 & 7.344 \\
\hline 11 & Overall Evaluation \& Believe & 1.3500 & 5.0600 & 6.831 \\
\hline & Total & & & 61.0609 \\
\hline
\end{tabular}

Table 1: Attitude towards the services of mobile phone in agricultural marketing $\left(\mathrm{A}_{0=} 61.0609\right)$

Through the asking questions to the farmer, we have found their overall attitude toward the mobile phone service in agricultural marketing. We can present overall attitude that customer that mobile phone regarding Market information is 8.0445 , immediate medication service of crops is 4.3803 , Transportation Information is 5.6974, storage \& maintenance is 3.2263 , weather anticipation is 7.3728 , Insect and danger kits identification and solicitation is 4.4528 , Procuring seed \& fertilizer is 5.0958 , Display \& communication is 6.096, Supplier selection \& solicitation is 2.52 , Mobile advertising \& promotion is 7.344, Overall evaluation \& Believe is 6.831. So we can say that market information, Weather anticipation, Mobile advertising \& promotion, Display \& communication, Procuring seed and Fertilizer holds the better position in user mind in mobile service in agricultural marketing 


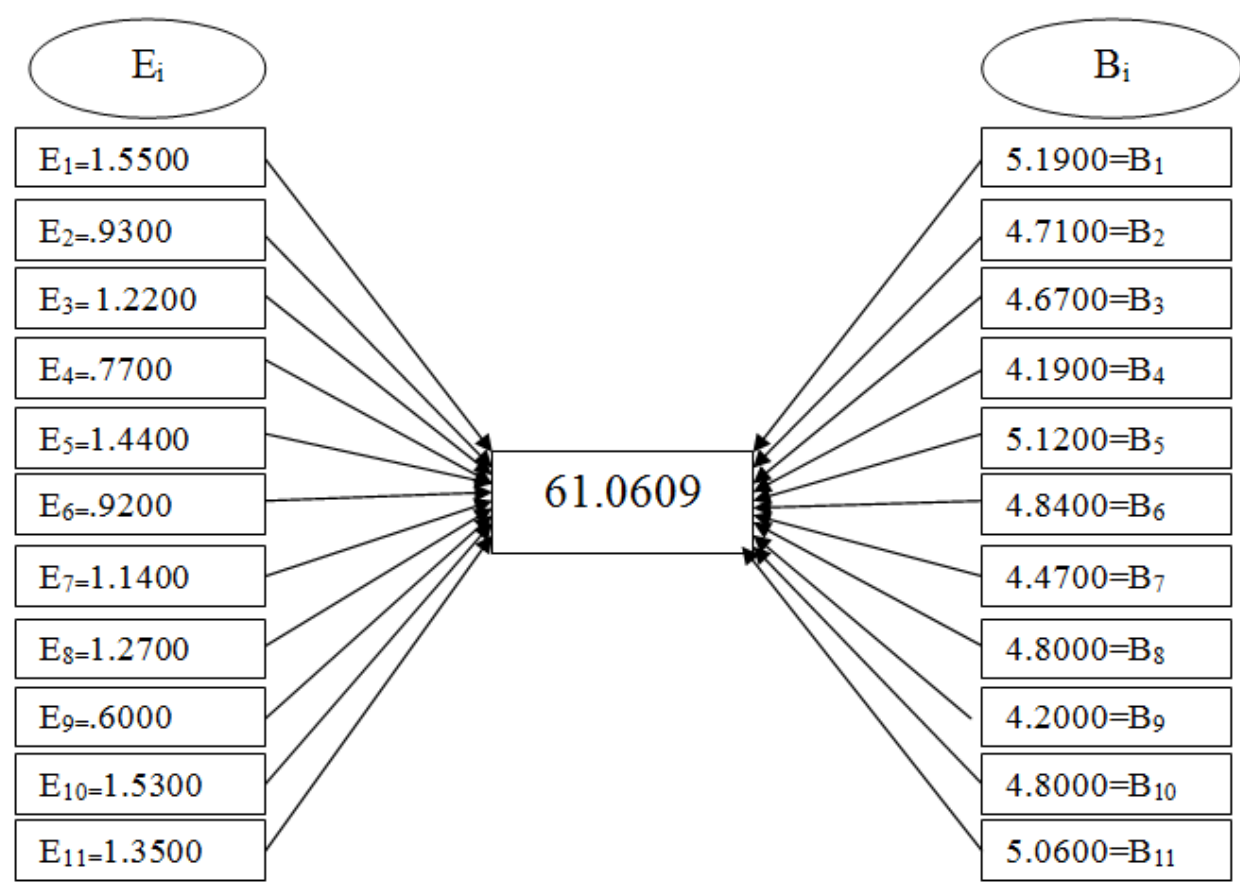

Figure 3: User's attitude toward the services of mobile phone in agricultural marketing

Above this figure, it has been found that users overall attribute towards the mobile phone in agricultural marketing is 61.0609. The study proves that user attribute towards the service of mobile phone in agricultural marketing is very useful because its covers average maximum percentage $(67.8 \%)$ through market information, immediate medication service of crops, transportation information, storage and maintenance, weather anticipation, insects and danger kits identification and solution, procuring seed and fertilizer, display and communication, supplier selection and solicitation, mobile advertising and promotion. So we can say that mean score of customer beliefs on various factors show different customer perception.

\section{New dimension of mobile phone to the agricultural marketing}

- Now a days, Mobile phone is used in as a remote control on water pump .

- Mobile phones changed farmers' cropping mix and marketing methods.

- It helps to quick response to any disruptions in the supply chain (for example, disruptions such as vehicle breakdowns clear up more rapidly).

- Mobile phone is helpful to create innovative partnership that gives the facility of direct communication with corporations and traders, or through the ability to supply product based on just-in-time and/or quality needs.

- Farmers' price gains are greater in areas close to the district center than in more remote areas, but the farther a farmer is located from the district center, the greater the impact of mobile phone coverage on market participation.

- Supporting the emergence of a more diverse rural economy, and supporting rural families ${ }^{\text { }}$ decisions about their mix of productive activities.

\section{Conclusion And Recommendations}

This study was initiated to examine the role of mobile phones as an empowering tool; a factor enhancing opportunities for increased income and a tool for reducing vulnerability to risks for smallholder crop farmers in rural areas of the developing countries. The experience we gained during data collection laid the groundwork for giving some recommendations on how mobile phone use can best continue to improve farmers life. Some information providers .The Ministry of Industry, Trade and Marketing, mobile phone service providers and the tobacco industry have tried to send updated market information via mobile phones to the farmers. Therefore, we recommend mobile phones companies to establish a wider, affordable and effective service or product offering instant market prices and additional, relevant market information. Prices printed in the newspapers are not useful for all farmers, because few farmers can, or have an interest of, buying newspapers. Efforts to control market prices through warehouse systems established by the government should be extended to crop farmers in Bangladesh. This will certainly increase their revenues and reduce much risk associated with travelling to market centers far away. One key element is that the service providers have to leverage the benefits of mobile phone such as portability, flexible content delivery capability and two way 
communications to deliver low-cost but highly customized solutions. Farmers must be able to get information delivered to them at a time and place of their choosing. Social networks like ITC may play an important role in building trust and confidence required to influence the adoption of new mindsets and actions by small farmers. Increased public and private investments will be necessary to bridge the critical infrastructural gaps.

\section{References}

[1]. Aker, Jenny C. \& Isaac Mbiti Summer (2010). Mobile phones and economic development inAfrica. Journal of Economic Perspectives. 24 (3), 207-232.

[2]. Aker, J. C. (2011). Dial "A" for agriculture: a review of information and communication technologies for agricultural extension in developing countries. Agricultural Economics, 42 (6), 631-647.

[3]. Ashraf, N., Gine, X. and Karlan, D. (2005). Growing Export Oriented Crops in Kenya: An Evaluation of Drum-Net Services. Ottawa: IDRC.

[4]. Bayes, A., von Braun, J. and Akhter, R., (1999). Village Pay Phones and Poverty Reduction: Insights from a Grameen Bank initiative in Bangladesh. ZEF discussion Papers on Development Policy No. 8 Centre for development Research, Bonn.

[5]. De Silva, H. (2008) Using ICTs to Create Efficiencies in Agricultural Markets: Some findings from Sri Lanka.In the proceeding of IDRC. May, 23 2008. Ottawa

[6]. Donner, J. (2008) Research Approaches to Mobile Use in the Developing World: A aGDP (2016) the largest employment in agricultural sector in Bangladesh., Available from: http://www. digitalbangladesh.gov.bd/documents/Education_chapter.pdf

[7]. Duncombe, R. (2011). Researching impact of mobile phones for development: concepts, methods and lessons for practice. Information technology for Development, 17 (4), 268-288.

[8]. Frempong, G., Essegbey, G. and Tetteh, E. (2007). Survey on the use of mobile telephones for Micro and Small Business Development: The Case of Ghana. Accra: CSIR Science and Technology Policy Research (STEPRI)

[9]. Lanjouw, J. O., \& Lanjouw, P. (2001). The rural non-farm sector: issues and evidence from developing countries. Agricultural Economics, 26(1), 1-23.

[10]. Samuel, O., Akinsola, Marlien, E. H., \& Jacob, S.J. (2005). ICT provision to disadvantaged urban communities: A study in South Africa and Nigeria. International Journal of Education and Development Using ICT, (1) 13-22. 